\title{
DIMENSÕES DA INFORMALIDADE EM BELÉM
}

\section{Ana Laura dos Santos Sena}

\section{Introdução}

Este artigo tem como objetivo mostrar algumas características da dinâmica interna de um segmento do mercado de trabalho informal em Belém - o dos vendedores ambulantes de produtos alimentícios -, mostrando, assim, as especificidades que a informalidade adquire em distintas formações sociais. $\mathrm{O}$ trabalho está dividido em seis partes, incluindo esta introdução. Na segunda parte serão mostrados os principais enfoques teóricos sobre a estruturação das atividades informais e também o papel delas no interior da estrutura de funcionamento do sistema capitalista; na terceira será esboçada uma breve análise sobre as mudanças no mercado de trabalho do Brasil a partir de 1990, com a abertura comercial e a intensificação do processo de reestruturação produtiva no país. A quarta parte tratará mais especificamente das características de funcionamento do comércio ambulante de produtos alimentícios em Belém, destacando alguns elementos importantes da estrutura de funcionamento destas

\footnotetext{
* Este artigo apresenta algumas questões discutidas na dissertação de mestrado "O trabalho informal nas ruas e praças de Belém: estudo sobre o comércio ambulante de produtos alimentícios", realizada sob a orientação da $\operatorname{Prof}^{a}$. Dra . Edna Castro.

*** Economista, mestre em planejamento do desenvolvimento e doutoranda do Núcleo de Altos Estudos Amazônicos.
} 
atividades e das relações entre os agentes econômicos que participam deste segmento do mercado de trabalho informal. A quinta e sexta partes, constituem respectivamente as considerações finais e as referências bibliográficas utilizadas.

\section{Fundamentos teóricos}

Para entender melhor o mercado de trabalho capitalista, é necessário estudar a forma de inserção da força de trabalho e as articulações estabelecidas entre os agentes econômicos (capitalistas e trabalhadores) e o Estado no interior do mercado de trabalho, que moldarão a estrutura do mesmo.

A dinâmica existente no mercado de trabalho, segundo Pires (1995, p. 2), resulta de vários fatores, tais como, opinião dos agentes econômicos sobre a possibilidade de inserção futura nas atividades produtivas, concorrência existente entre os empresários capitalistas, oferta de mão-de-obra no mercado, tipo de divisão técnica presente no desenvolvimento das atividades produtivas, implantação de inovações tecnológicas, adoção de processos de reestruturação produtiva por parte das empresas, nível cultural da sociedade, e o tipo de relação que se estabelece entre trabalhadores, capitalistas e governo.

No mercado de trabalho, pode ser observado que determinadas relações entre os agentes, para implementar as atividades produtivas, estão perfeitamente adequadas às normas capitalistas de produção (leis definidas pelo Estado), enquanto que outras relações se desenvolvem de uma maneira diferenciada, não se inserindo diretamente dentro de alguns ou em nenhum dos regulamentos legais definidos. Desta maneira, no mercado de trabalho capitalista encontram-se acordos (contratos) estabelecidos entre os agentes econômicos que se enquadrariam na denominação de "formais" e outros de "informais", em que os primeiros seguem diretamente as normais legais definidas para o desenvolvimento das atividades produtivas, e os últimos encontram-se parcialmente ou totalmente à margem das determinações legais.

Para a compreensão, portanto, de forma mais completa da dinâmica do mercado de trabalho, é necessário que se tenha a percepção da totalidade do funcionamento deste mercado e do papel dos acordos formais e informais, que darão origem aos mercados de trabalho formal e informal. Neste contexto, é interessante ressaltar que as atividades informais apresentam também determinadas características específicas para se adequarem às diferentes formações sociais em que se desenvolvem.

A primeira dificuldade para se compreender o setor informal (SI) reside nos inúmeros conceitos existentes que procuram definir esse conjunto de 
atividades que são desempenhadas pelos agentes econômicos no interior do sistema capitalista. A grande quantidade de atividades desenvolvidas no SI bem como a sua diversidade qualitativa dificultam a elaboração de um único conceito, fazendo com que, em geral, grande parte das tentativas de definição deste setor terminem privilegiando apenas um aspecto das atividades produtivas informais, o que causa, muitas vezes, a generalização de conceitos que estão muito distantes da realidade do SI.

Desta maneira, o SI tem de ser analisado como um tipo de estratégia utilizada tanto pelos trabalhadores como pelo capital para se reproduzir, sendo que as atividades informais não podem ser vistas simplesmente como responsáveis por uma concorrência desleal para com as atividades formais. Neste sentido, o SI está ligado à dinâmica de desenvolvimento do setor formal (SF), não podendo ser analisado de forma separada e como uma estrutura oposta (relação dualista) ao SF.

As atividades informais estão subordinadas à lógica de funcionamento do sistema; desta maneira, os preceitos da lógica do capital terminam por determinar também as condições em que são desenvolvidas as atividades informais (jomada de trabalho, base para o cálculo do rendimento, insumos e equipamentos utilizados etc., nas atividades informais). Deve-se questionar, assim, até que ponto o tipo de relação que se tem observado no mercado de trabalho informal, por exemplo, entre patrão e empregado informais, não pode representar uma nova forma de subordinação do capital ao trabalho para enfrentar processos de crises econômicas (Casimiro 1985, p. 180).

No primeiro trabalho em que o SI foi mencionado - Employmente, incomes and equality: a strategy for increasing productive employment in Kenia, Organização Internacional do Trabalho - 1972 - , as relações que se supuseram existir entre o SI e o SF considerou o primeiro como um setor evolucionário, que poderia crescer e até gerar alguma acumulação, mas no interior de uma análise dual e estática, que via sempre uma relação de oposição entre as atividades formais e informais, sendo estas últimas passageiras e tendentes a desaparecer com o desenvolvimento econômico (Cacciamali 1990, p. 833834).

Neste enfoque tradicional, o SI é considerado como formado por atividades a que nâo existem barreiras à entrada, a produção ocorre em pequena escala, a tecnologia utilizada na produção é pouca e as atividades são intensivas em trabalho, as unidades de produção são familiares e a estrutura de mercado é concorrencial e não regulada. Neste contexto, o SI é constituído por um conjunto de empresas e/ou pessoas ocupadas em atividades não organizadas (tanto do 
ponto de vista capitalista - em que o proprietário do capital e do trabalho é o mesmo - como no sentido de não organizada juridicamente).

Um outro enfoque sobre o SI, reforçado com o crescimento do pensamento neoliberal, está ligado ao dimensionamento do volume das atividades informais à parcela da evasão das receitas tributárias e à parcela não computada do Produto Nacional Bruto (PNB). Neste contexto, as atividades informais são consideradas como atividades não declaradas ou ilegais, mas necessariamente lícitas ${ }^{1}$; o elemento que faz com que elas permaneçam fora da legalidade reside na excessiva regulação estatal, principalmente no aspecto da determinação dos salários. O SI se constituiria, então, em uma saída para escapar dessa pesada regulação estatal (Carneiro 1994, p. 44). Segundo Carneiro (1994 p. 48) "trata-se, pois, de espaços formais que se tornam informais e mantêm sua própria dinâmica, sendo de alguma forma "centrais', e não "periféricos"”.

Uma outra abordagem procura estudar as atividades informais a partir da natureza das relações de produção presentes em suas atividades. Neste enfoque, o SI se caracteriza por uma organização específica dos fatores produtivos, sendo que em grande parte das atividades informais o produtor direto dos bens e serviços também é o dono dos meios de produção que utiliza no interior do processo; o SI passa a ser analisado "a partir das relações de trabalho com os meios de produção" (Cacciamali 1990, p. 835).

Segundo este último enfoque, no SI pode-se identificar uma diferenciação das relações de trabalho desenvolvidas com os meios de produção quando comparadas às do SF. Isto é mais facilmente percebido em algumas atividades do que em outras (caso dos trabalhadores por conta própria e trabalhadores familiares, por exemplo), pois existem atividades informais muito parecidas com atividades formais quando se destaca este aspecto da relação dos trabalhadores com os meios de produção (caso dos trabalhadores assalariados sem carteira de trabalho assinada). Essa abordagem, quando comparada aos enfoques dual e neoliberal sobre o SI, apresenta uma análise mais abrangente por levar em consideração esse aspecto da diferenciação interna das atividades informais e da influência disso nas relações de trabalho entre os agentes produtivos.

Essa pluralidade analítico-teórica dos estudos sobre este assunto serve para destacar como podem ser observadas as distintas dimensões da informalidade presentes em espaços sociais específicos (Cheng; Gereffi 1994, p. 199).

\footnotetext{
${ }^{1}$ A diferenciação entre que atividades poderiam ser consideradas ilegais e lícitas ou ilegais, mas ilícitas não fica muito clara neste enfoque sobre o SI, constituindo-se em fonte de críticas a ele.
} 


\section{Mercado de trabalho brasileiro a partir de 1990}

No começo da década de 1970, tem início o delineamento de um processo crescente de reestruturação econômica na economia mundial, que teve grandes repercussões sobre a estrutura organizacional e normas de gerenciamento dos fatores de produção utilizados na geração de bens e serviços. Estas transformações vieram a colocar em xeque os princípios norteadores do funcionamento do regime fordista de produção até então dominante.

As mudanças que podem ser observadas no mercado de trabalho a partir dos anos 90 são diferentes das que ocorreram no período recessivo da década de 80. Na década de 80, a informalização foi caracterizada pelo crescimento dos trabalhadores sem carteira assinada; nos anos 90, essa situação vem ocorrendo principalmente através do aumento do número de trabalhadores por conta própria (Sabóia, 1995, p. 16). No princípio dos anos 90, é observado também que o governo brasileiro começa a implantar um novo modelo de desenvolvimento para o país, com o processo de abertura da economia objetivando uma maior integração do Brasil ao comércio internacional.

Da mesma forma que o fordismo, a implementação do modelo japonês no Brasil assume determinadas características nacionais (Druck, 1995, p. 2), de acordo com as particularidades existentes na economia brasileira, sendo que a adoção de programas de qualidade total, just-in-time, downsizing, cinco Ss, terceirização etc., vêm apresentando uma maior difusão entre os vários tipos de empresa que compõem o mercado nacional. Entretanto, é verificado também em muitas firmas a convivência das práticas antigas com as novas formas de gestão da produção e de certas modificações operadas nos preceitos de algumas dessas novas formas de gestão, dificultando a maior difusão das inovações e aumentando os problemas do mercado de trabalho, tais como o aumento da precariedade.

Não há dúvida de que a crescente diversificação da força de trabalho e de suas modalidades de contratação é uma das principais novidades registradas nos últimos anos. Nada se sabe sobre a que lugar este processo conduzirá, mas podem imaginar-se dois extremos: a diversidade atual poderia servir para que se planejem meios de fomentar novas oportunidades em favor das novas categorias de trabalhadores, ou poderia gerar a criação de duas classes de assalariados constituídas, respectivamente, por uma categoria cada vez mais limitada de empregados bem remunerados e estáveis e outra composta de grupos muito mais numerosos de trabalhadores menos remunerados, pouco qualificados, privados de seguridade no emprego e muito menos leais a seus empregadores (Locke; Kochan; Piore 1995, p.172). 
A dificuldade da economia brasileira em criar empregos na quantidade e com a qualidade necessárias ao funcionamento adequada da estrutura produtiva é hoje um dos principais problemas enfrentados no país. Desta forma, tanto a configuração da estrutura ocupacional existente como o problema do desemprego estão diretamente relacionados com as deficiências estruturais presentes na formação da própria economia brasileira (Pires 1996, p. 10). Assim, questões relacionadas à precarização, flexibilidade, desregulamentação e crescimento de atividades informais não podem ser caracterizadas somente como condicionantes de ordem conjuntural; neste sentido, o desemprego tem assumido uma nova dimensão de desemprego estrutural (Castro, 1994 p. 2) $)^{2}$.

Desta forma, a fragilidade e insegurança presentes no mercado de trabalho nacional fazem com que ele adquira uma configuração própria. As estratégias encontradas pelos trabalhadores para continuar participando desse mercado. demonstram a incapacidade dos trabalhadores desempregados em manter a situação de desemprego aberto, a que torna mais complexa a dinâmica do desemprego e suas formas de manifestação no Brasil (Dedecca 1996, p. 54).

\section{Atividades informais em Belém}

Desde o início do desenvolvimento do processo capitalista, Belém se constituiu no centro urbano mais importante daAmazônia. Contudo, as deficiências infra-estruturais (uma vez que a estrutura urbana implantada pelo governo federal mostrou-se insuficiente para absorver satisfatoriamente a crescente volume de população migrante) presentes na cidade impactaram diretamente no tipo de atividade produtiva que se desenvolveu.

As consequiências deste processo de integração da região ao capitalismo, ou seja, da implantação de sistemas de urbanização para servir exclusivamente de apoio às atividades desenvolvidas pelo capital internacional, fizeram com que fosse implantada, tanto em Belém como nos demais centros urbanos daAmazônia, um

\footnotetext{
${ }^{2}$ Deve-se destacar que a implementação do Plano Real, a partir do segundo semestre de 1994, trouxe mudanças significativas para a economia nacional, a baixa da taxa de inflação possibilitou um novo dinamismo às atividades produtivas, Entretanto, em razão do aprofundamento do processo de reestruturação produtiva e as especificidades da economia brasileira, tem-se observado que o crescimento da economia tem ocorrido em taxas pequenas. Tratando-se mais especificamente do mercado de trabalho, vem sendo observado um aumento do desemprego no país; apesar das diferenças dos percentuais mostrados pelas diferentes pesquisas sobre o mercado de trabalho nacional, a tendência de crescimento do desemprego é um fato comum aos estudos feitos, A partir de 1995, segundo dados da Pesquisa Mensal de Emprego (PME), realizada pela Fundação Instituto Brasileiro de Geografia e Estatística (IBGE) a taxa de desemprego foi de 4,65\% em 1995, 5,43\% em 1996 e 5,67\% em 1997; em janeiro de 1998, a taxa de desemprego ficou em 7,25\%.
} 
capitalismo de enclave que, junto com a concentração fundiária, desencadeia um processo de proletarizaçâo passiva, isto é, a dissolução das tradicionais formas de (re) produção, que para a grande maioria dos produtores diretos não se traduz em uma perspectiva de assalariamento formal de trabalho. (Mitschein; Miranda; Paraense 1989, p. 23).

A heterogeneidade dos tipos de inserção das pessoas nas atividades informais que estão presentes no mercado de trabalho de Belém revelam as novas formas de articulação que vêm se estabelecendo entre os agentes produtivos para enfrentar as dificuldades presentes no mercado de trabalho local, causadas pela constituição da estrutura produtiva, que influencia nos empregos gerados no mercado formal e, consequientemente, nas ocupações que são também desenvolvidas no mercado informal. As características da força de trabalho presente no mercado também fazem com que os agentes produtivos (capitalistas e trabalhadores) e o Estado desenvolvam estratégias específicas para o desenvolvimento das atividades (tanto formais quanto informais).

Neste contexto, o crescimento do comércio ambulante em Belém, ao revelar a criação de novos espaços produtivos para o desenvolvimento das atividades informais, demonstra uma determinada dinâmica de funcionamento do mercado de trabalho local. Em Belém, é observada a existência de uma grande concentração de trabalhadores ambulantes na área denominada de quadrilátero do centro comercial ${ }^{3}$, devido ao alto número de estabelecimentos comerciais existentes nesta área, que atraem diariamente uma grande quantidade de pessoas, sendo as atividades desenvolvidas pelo comércio ambulante informal as mais diversas: venda de confecções, bijouterias, animais, plantas, brinquedos, alimentos, calçados, utensílios domésticos, materiais elétricos, ferragens etc.

Em geral, os vendedores ambulantes se concentram próximos de paradas de ônibus, escolas, cinemas, lojas, shoppings, praças, alguns pontos turísticos no centro de Belém etc. - enfim, locais em que o fluxo de pessoas que transitam é grande, propiciando a constituição de um mercado consumidor para estas atividades informais (paralelo ao desenvolvimento das atividades formais). Neste sentido, deve-se destacar que o público consumidor para os produtos comercializados também é expressivo, caso contrário, essas atividades não teriam

${ }^{3}$ O quadrilátero envolve os seguintes locais: Av. Assis de Vasconcelos, Av. Boulevard Castilhos Prança, Av. Portugal até a Rua 16 de Novembro, Av. Almirante Tamandaré, Trav. Padre Eutíquio e Praça Batista Campos, retomando pela Av. Serzedelo Corrêa até a Av. Assis de Vasconcelos novamente e todas as transversais existentes nesse perímetro. 
como se desenvolver e permanecer, sendo este mercado consumidor tão heterogêneo quanto os produtos vendidos. (Deseja-se, assim, enfatizar que muitas das mercadorias comercializadas nas ruas e praças de Belém não são consumidas exclusivamente por pessoas de baixa renda).

Neste sentido, a base para o conhecimento um pouco mais aprofundado das características deste segmento do mercado de trabalho informal e que originaram as observações seguintes foi a pesquisa de campo feita com 218 vendedores ambulantes de alimentos em alguns locais de Belém ${ }^{4}$. A pesquisa teve como principal objetivo tentar fornecer subsídios sobre a forma de estruturação deste segmento do mercado de trabalho e entender a relação entre SF e SI a partir desse segmento das atividades informais.

Desta maneira, objetivando esclarecer a estrutura de funcionamento do segmento do mercado de trabalho que envolve os vendedores ambulantes de produtos alimentícios, a apresentação das posições dos agentes que interagem neste segmento do mercado de trabalho - trabalhadores, empresários e Estado -, da maneira como são identificados no comércio ambulante - vendedores ambulantes, donos de estabelecimentos comerciais e legislação/Secretaria Municipal de Economia (SECON)-, são essenciais para que sua dinâmica interna de organização possa ser melhor compreendida ,

Entre os vendedores ambulantes de alimentos, é observada a existência, de trabalhadores autônomos, trabalhadores assalariados informais e também de pequenos produtores informais, que assalariam informalmente outros trabalhadores. Estas diferentes categorias de ambulantes, apesar de não poderem ser identificadas facilmente quando se observam os trabalhadores nas ruas e praças, influenciam significativamente na maneira como as atividades são desenvolvidas e ajudam a entender a proximidade e interação existente entre essas atividades do comércio ambulante e as atividades formais. É observado, assim, que, trabalhando lado a lado e concorrendo diretamente com os autônomos, são encontrados trabalhadores que estão inseridos em uma relação capitalista que, em sua gênese, funciona da mesma forma que a relação assalariada capitalista. Aúnica diferença está na ausência da carteira de trabalho assinada, ou seja, no não cumprimento das normas legais definidas pelo sistema para a intermediação das relações de trabalho.

\footnotetext{
${ }^{3}$ Informações mais detalhadas sobre a metodologia utilizada e os lugares em que foi realizada a pesquisa de campo são encontradas em Sena (1998).

${ }^{4}$ Neste artigo, serão enfatizados somente alguns pontos relacionados aos vendedores ambulantes, por isso as posições dos empresários e SECON não serão mostradas.
} 
Observa-se, assim, que existe uma rede de "contratação" de trabalhadores que atuam como vendedores ambulantes em Belém por pessoas que são proprietárias de vários pontos e/ou bancas (licenciados ou não) e dos equipamentos e/ou instrumentos utilizados nas atividades, que assalariam trabalhadores para venderem produtos alimentícios nas vias públicas, demonstrando uma das formas de organização existente neste segmento do mercado de trabalho informal. Essa rede de "contratação" de trabalhadores assalariados, juntamente com a inserção de trabalhadores autônomos, fazem parte da dinâmica de funcionamento deste segmento do mercado de trabalho informal.

Entre os trabalhadores que foram entrevistados, $76,1 \%$ era composto de homens e 23,6\% de mulheres, predominando os chefes de família no desenvolvimento das atividades do comércio ambulante, sendo que entre os homens tambémé registrado o maior percentual de chefes de família, configurando o fato de esta ocupação informal envolver os principais responsáveis pela renda familiar. A Tabela 1 mostra o baixo grau de escolaridade existente entre os vendedores ambulantes, o que termina influenciando nas dificuldades enfrentadas por estes trabalhadores para obter melhores postos de trabalho.

Tabela 1: Distribuição percentual dos vendedores ambulantes, segundo o grau de escolaridade - Belém - Dez. 97.

\begin{tabular}{l|r|r|r}
\hline \multirow{2}{*}{ ESCOLARIDADE } & \multirow{2}{*}{ TOTAL } & \multicolumn{2}{|c}{ AINDA ESTUDA } \\
\cline { 3 - 4 } & & \multicolumn{1}{|c}{ SIM } & \multicolumn{1}{c}{ NÃ O } \\
\hline Não freqüentou escola e não sabe ler e escrever & 3,2 & - & - \\
Não freqüentou escola, mas sabe ler e escrever & 0,9 & - & - \\
$1^{\mathbf{0}}$ grau incompleto & 70,4 & 12,1 & 58,3 \\
$1^{\mathbf{o}}$ grau completo & 8,8 & 0,9 & 7,9 \\
$2^{\mathbf{o}}$ grau incompleto & 7,9 & 2,8 & 5,1 \\
$2^{\mathbf{o}}$ grau completo & 8,8 & 0,5 & 8,3 \\
Total & 100 & 16,2 & 83,8 \\
\hline
\end{tabular}

Fonte: Pesquisa direta

As horas médias trabalhadas diariamente por estes trabalhadores informais indicam que a sua jornada de trabalho é muito extensa, trabalham em geral cerca de 11 horas por dia. Este dado serve também para que se comece a questionar a idéia de que as pessoas que estão ocupadas em atividades informais, em geral, cumprem uma jornada de trabalho irregular com poucas horas trabalhadas usualmente. Contrariando o pensamento bastante difundido de que os trabalhadores informais não têm um horário regular de trabalho, para 73,4\% dos 
trabalhadores entrevistados seu horário de trabalho permanece o mesmo durante a semana (principalmente no caso dos trabalhadores assalariados informais), enquanto que somente $26,6 \%$ declararam ocorrer mudanças em seu horário de trabalho.

Tabela 2: Rendimentos normalmente obtidos pelos vendedores ambulantes durante o mês - Belém - Dez. 97.

\begin{tabular}{l|c}
\hline \multicolumn{1}{c|}{ Rendimento } & $\mathbf{\%}$ \\
\hline Até 1 S.M.* & 15,2 \\
Mais de 1 S.M. até 2 S.M. & 36,9 \\
Mais de 2 S.M. até 3 S.M. & 13,1 \\
Mais de 3 S.M. até 5 S.M. & 18,2 \\
Mais de 5 S.M. até 10 S.M. & 13,1 \\
Mais de 10 S.M. & 3,5 \\
\hline
\end{tabular}

Fonte: Pesquisa direta.

* S.M. salário mínimo.

A Tabela 2 revela que a maioria dos trabalhadores se consentra na faixa dos que ganham de 1 até 2 salários mínimos . A medida do rendimento mensal obtido pelos trabalhadores deste segmento produtivo é de $\mathrm{R} \$ 353,89$.

Em relação aos meios de produção utilizados para o desenvolvimento da atividade do comércio ambulante, $67 \%$ dos entrevistados declarou ser o proprietário das bancas e/ou do ponto para iniciar a atividade, o que não significa que estejam licenciados na SECON, isto somente reforça a observação de que os recursos necessários para iniciar a atividade, em geral, são acessíveis para a maioria dos trabalhadores.

Tabela 3: Meios utilizados pelos vendedores ambulantes para conseguir o ponto - Belém - dez. 97.

\begin{tabular}{l|c}
\hline \multicolumn{1}{c|}{ Meios utilizados } & \% \\
\hline Simplesmente colocou a banca e ficou no local sem a licença & 37,2 \\
Através da licença da Prefeitura & 36,2 \\
Entrou em um acordo com os outros ambulantes para conseguir o local & 6,0 \\
Através de conhecidos (amigos, patente) & 5,0 \\
Através da prefeitura & 4,6 \\
Comprou o ponto & 2,3 \\
Autorização da SECON & 0,9 \\
Não sabe & 1,4 \\
Outros & 6,4 \\
\hline
\end{tabular}

Fonte: Pesquisa direta.

\footnotetext{
${ }^{6}$ Segundo dados da PNAD/95, os trabalhadores brasileiros concentram-se na faixa dos que recebem de 1 a 2 salários mínimos por mês.
} 
A Tabela 3 exemplifica que a precariedade no desenvolvimento destas ocupações é muito grande e que as determinações legais para o estabelecimento ou não do ponto não obedece a um planejamento sobre quais os lugares onde essas atividades poderiam ser desenvolvidas de uma forma mais ordenada pela Prefeitura. Apesar do significativo percentual que afirmou ter conseguido o ponto obtendo a licença legal $(36,2 \%)$, nota-se que existe uma idéia muito forte entre os vendedores da importância da ação individual de conquista do espaço físico para desenvolver a atividade, conforme demonstram os 37,2\% que afirmaram ter simplesmente se estabelecido na via pública, apropriado-se e transformado a rua em seu local de trabalho.

Tabela 4: Vendedores ambulantes sindicalizados segundo o sindicato - Belém Dez. 97.

\begin{tabular}{l|c}
\hline \multicolumn{1}{c|}{ Sindicato } & \% \\
\hline Associação dos ambulantes do Centro Comercial & 3,2 \\
Sindicato dos Feirantes & 0,5 \\
Sindicato dos Balconistas & 0,5 \\
Sindicato dos Trabalhadores do Mercado Informal de Belém & 11,5 \\
Total sindicalizados & 15,6 \\
Total não sindicalizados & 84,4 \\
\hline
\end{tabular}

Fonte: Pesquisa direta.

Obs.: 41 vendedores ambulantes se declaram sindicalizados, mas 7 não especificaram o sindicato ao qual eram filiados.

A Tabela 4 mostra o reduzido grau de organização coletiva existente entre os trabalhadores informais. Esta baixa capacidade de se organizar para lutar por seus interesses faz com que o atendimento de suas reivindicações seja dificultado e que eles tenham muitos problemas para negociar sobre sua situação com as autoridades municipais. Observa-se que a noção de associação entre os vendedores ainda não está muito desenvolvida, o que tem reflexos na maneira como avaliam as vantagens e desvantagens que isto pode ter.

Os ambulantes, apesar das dificuldades internas, têm procurado se organizar coletivamente para tentar fazer com que suas reivindicações sejam aceitas pela SECON, que representa a Prefeitura. Observa-se que a constituição do Sindicato dos Trabalhadores do Mercado Informal de Belém (SINTMIB), que agrega não somente os trabalhadores do comércio ambulante, mas qualquer

\footnotetext{
7Em geral, a SECON tem muitas dificuldades para retirar os ambulantes dos pontos já "escolhidos" por esses trabalhadores, pois, na maioria das vezes, é somente depois de algum tempo em que eles já estão estabelecidos nesses locais - de terem conseguido delimitar o seu espaço físico de trabalho - que os trabalhadores se preocupam em legalizar sua situação.
} 
trabalhador informal, e a posição de liderança que este tem assumido entre os vendedores ambulantes pode vir futuramente a influenciar nas relações dos trabalhadores com a SECON e os empresários.

A posição da SECON, de tentar fazer com que as normas legais sejam cumpridas, reflete o pensamento do Estado - Prefeitura - de como devem ser organizadas estas atividades informais, o que, ao procurar modificar algumas das bases de estruturação dessas atividades, termina por causar conflitos entre a SECON e estes trabalhadores. E esta relação conflituosa entre o Estado e os trabalhadores se torna mais evidente nos conflitos que ocorrem entre os fiscais da SECON e os vendedores ambulantes durante as ações de fiscalização feitas diariamente.

Em suma, pode-se identificar que o ramo do comércio ambulante que abrange os vendedores de produtos alimentícios possui características específicas que possibilitam sua estruturação e funcionamento. Neste sentido, é, então, observado que existe uma grande precariedade neste segmento do mercado de trabalho, pois as condições de trabalho são, em geral, ruins e os rendimentos obtidos são baixos (embora existam exceções); essas atividades constituem uma importante fonte de ocupação e renda para os trabalhadores que estão envolvidos nelas. Este segmento do SI apresenta também uma estrutura própria de organização para o desenvolvimento de suas atividades (que se reflete na escolha dos locais, na disposição dos ambulantes nas vias públicas, no tipo de mercadoria vendida, no horário de trabalho etc.), as quais funcionam de maneira interativa com as atividades formais (sendo subordinadas às atividades formais em última instância). Em geral, os vendedores ambulantes de alimentos - e o comércio ambulante como um todo - se concentram em locais em que há um fluxo muito intenso de pessoas, existindo uma grande concorrência entre os trabalhadores que desenvolvem tais atividades.

\section{Considerações finais}

Este artigo procurou mostrar de maneira muito breve alguns dos elementos que compõem a estrutura de funcionamento do segmento dos vendedores ambulantes de produtos alimentícios de Belém. Objetivou-se destacar que a informalização existente no mercado de trabalho possui aspectos que, muitas vezes, não conseguem ser captados pelas teorias sobre o SI, daí a necessidade de mudanças.

O segmento do comércio informal de vendedores alimentícios exemplifica a dinâmica de funcionamento e a complexidade de estruturação existentes no 
interior das atividades informais e nas relações entre os agentes econômicos que possibilitam o desenvolvimento das mesmas, que terminam configurando um quadro diferente da aparente simplicidade que as atividades do comércio ambulante demonstram em um primeiro momento. Oconhecimento mais profundo de seus aspectos permite compreender um pouco mais a dinâmica do mercado de trabalho de Belém.

\section{Referências Bibliográficas}

BRASIL. Ministério do Trabalho; Instituto de Pesquisa Econômica Aplicada. Mercado de trabalho: conjuntura e análise, Rio de Janeiro: IPEA, a. 3, n.7, fev. 1998.

CACCIAMALI, M. C. Setor informal e formas de participação na produção: o caso do município de São Paulo. In: Encontro Nacional de Economia, 10, 1982, Águas de São Pedro. Anais... São Paulo: Editora Universitária, 1982, p.15-43.

As economias informal e submersa: conceitos e distribuição de renda. In: Encontro Nacional de Economia, 18, 1990, Brasília. Anais... Belo Horizonte: MGSP Editores, 1990, p.831-850.

CARNEIRO, Francisco G. Informalidade e terceirização: duas tendências opostas? Revista de Economia Política, Rio de Janeiro, v. 14, n. 4, p. 4l-49, out./dez. 1994.

CASIMIRA, Liana Maria Carleial. Acumulação capitalista, emprego e crise: um estudo de caso. São Paulo, 1985. Tese (Doutorado). Departamento de Economia. Faculdade de Administração e Economia. Universidade de São Paulo, 1985.

CASTRO, Edna. Industrialização, transformações sociais e mercado de trabalho. Belém, NAEA, 1994 (paper do NAEA n.23).

CHENG, Lu-Lin; Gereffi, Gary. The informal economy in East Asian develoment. International Journal of Urban and Regional Research. Blackwell Publishers - Oxford UK and Cambridge USA, v.8, n.2, p.194-219, jun. 1994.

DEDECCA, Claudio S. Desemprego e regulação no Brasil hoje. Campinas: Instituto de Economia, n. 20, 1996 (Cadernos do CESIT, n020).

DRUCK, Maria da Graça. A “cultura da qualidade” nos anos 90: o caso da indústria petroquímica da Bahia. Bahia, 1995. (mimeo.)

LOCKE, Richard; KOCHAN, Thomas; PIORE, Michael. Replanteamiento del Estúdio comparado de las relaciones laborales: Ensenanzas de una investigación internacional. Revista Internacional del Trabajo, Genebra, v.114, n.2, p.157 $183,1995$. 
SCHEIN, Thomas A; MIRANDA, Henrique R.; PARAENSE, Mariceli C. Urbanização selvagem e proletarização passiva na Amazônia: o caso de Belém. Belém: CEJUP, 1989.

PIRES, Elson Luciano Silva. Ciclos, metamorfoses e regulação: breve histórico das relações capitalistas no Brasil. São Paulo, 1995 (mimeo.).

PIRES, Júlio. Desemprego: características e políticas públicas. São Paulo, 1996. (mimeo.).

SENA, Ana Laura dos Santos. O trabalho informal nas ruas e praças de Belém: estudo sobre comércio ambulante de produtos alimentícios. Belém, 1998. Dissertação (Mestrado em Planejamento do Desenvolvimento). Núcleo de Altos Estudos Amazônicos. Universidade Federal do Pará, 1998. 